\title{
Interviewing Disaffected Students with "Talking Stones"
}

\author{
Professor Janice Wearmouth \\ Faculty of Education, Victoria University of Wellington
}

\begin{abstract}
"Talking Stones" is an interview technique that is designed to support self advocacy, particularly for groups of disaffected school students whose views may be difficult to elicit. It has been developed and refined to incorporate a view of learners as active agents in their own learning and is compatible with reflective practice and a social constructivist view of mind. The technique enables individuals to invest their own meaning in concrete objects which have no intrinsic meaning themselves apart from their own "stone-ness". Stones do not make the same demands as face to face conversations in terms of communication skills. They have texture, size, shape and colour and enable students to articulate their feelings about themselves in relation to school in ways that may not previously have been open to them. The current paper illustrates how "Talking Stones" lends itself to practice in schools by laying bare problematic relationships and opening up dialogue between, typically, teenagers and staff.
\end{abstract}

\section{Practice Paper \\ Keywords}

Behaviour problems, ethics, inclusion practices, interviewing, school based intervention, self concept, self esteem, social constructivism, student behaviour.

\section{INTRODUCTION}

Across the world there is a long history of concern about disruptive, challenging behaviour by school students. In the United Kingdom, for example, in the seventeenth century, students were often armed and there were occasions when they took part in violent mutiny in their schools (Furlong, 1985). According to Ogilvie (1957), students destroyed all the most famous private schools at least once.

As soon as education has become compulsory in a country, controlling the behaviour of students assumes paramount importance (Ford, Mongon \& Whelan, 1982). Approaches to educational provision for students seen as experiencing emotional and behavioural difficulties depend on current ways of understanding human behaviour and learning. Over the years official responses to behaviour experienced as problematic in schools have varied considerably. The kind of provision that is made really matters. Potentially it can be life-changing, for the better or the worse. Interventions for these students might be punitive and harsh, rehabilitative or therapeutic. For example, there are applied behavioural practices associated with understanding of behaviour as being controlled by external events. There are also educational or therapeutic practices associated with holistic or humanistic understandings (Cole, 2004).

As Murphy (1995) notes, the dominant view of learning in education over the last few decades has been constructivist. The key principles include the view that knowledge is not passively received by students but actively built up by them. 'Thus we do not find truth but construct viable explanations of our experiences' (Wheatley, 1991, p.10). Taken to its extreme this means that there is no reality outside an individual's mental construction. A teacher cannot know what goes on in students' heads, but constructs models of what he or she believes to be going on. Teachers give meaning to students' actions and responses. The same is true of students, who, in their turn, give meaning to teachers' actions and words (Murphy, 1995).

In recent years a number of researchers have made clear their understanding that the study of individual learning and behaviour cannot be considered in isolation from their social and historical context (Matthews, 1993). Research on sociocultural approaches to learning and behaviour has therefore become increasingly common among educationalists trying to understand how to promote effective teaching (Murphy, 1995). 'The basic goal of a sociocultural approach to mind is to create an account of human mental processes that recognises the essential relationship between these processes and their cultural, historical and institutional settings' (Wersch, 1991, p. 6). From a sociocultural view concepts are socially determined and socially acquired.

Both constructivist and sociocultural theories are currently exerting considerable influence in educational practice. Common to both perspectives is the view that the process of coming to know is constructive. This means that students are actively engaged in thinking and that the ideas and experiences they bring to situations matter.

Schools play a critical part in shaping students' beliefs in their sense of self efficacy, that is their ability, responsibility and skill in initiating and completing actions and tasks. The way schools mediate success and failure are crucial to the development of a sense of personal agency (Bruner, 1996). The sense of belonging to, or marginalisation from, that community affects every aspect of participation and, therefore, learning within it, and necessarily affects a student's behaviour and self perception. Failing to support 
the development of students' understanding and ability to act in a social context risks marginalising and alienating young people and rendering them incompetent (Wearmouth, Glynn \& Berryman, 2004).

Not addressing the "problems" of non-engagement with their education of significant numbers of disaffected students costs society dearly "both in terms of reduced economic contribution in adult life and. for some, of criminal activity and prison' (Department for Education and Employment, 1997, p. 78). Research from a number of countries, for example, New Zealand (Ministry of Education, 2001), England (Department for Education and Employment, 1997), Wales (National Assembly for Wales Education Department, 2001), Scotland (Munn, Cullen, Johnstone \& Lloyd, 2001) and Ireland (Fahy-Bates, 1990; Rudd, 1972; Swan, 1978) has repeatedly shown the detrimental effects of school exclusion to the welfare and future life chances of young people. In some cases, low attendance has been linked to the curtailment of opportunities for educational achievement and qualification and, thus, entry into further education and/or employment.

Research such as this highlights the need to address the issue of school attendance and student disaffection and overall levels of school achievement. These issues are mutually reinforcing. To prevent and deal with them effectively, they, together with the general problem of educational disadvantage, require good intervention programmes.

\section{CHALLENGES IN STUDENT SELF ADVOCACY IN SCHOOLS}

Taking the young person's view seriously and attempting to understand his/her perspective is essential to any consideration of how we might understand and address student behaviour that is experienced as problematic in schools (Wearmouth, et al, 2004). It is not always easy to engage with students whose behaviour in schools is experienced as challenging or otherwise worrying. Nevertheless these students have the same basic needs as any other.

Account needs to be taken of how children make sense of their own circumstances and what impression is conveyed to students of others' constructions of them. Everyone both creates his/her own world and is created by it and by others around (Ravenette, 1984). As children actively engage in social interaction we need to be concerned with what they themselves make of the circumstance in which they find themselves in school.

However, ascertaining the child's views 'may not always be easy' (Department for Education and Employment, 2001, 3:3). In many schools professionals will have encountered students with whom communication has been difficult:

Many are socially isolated and, to judge by body language, feel appalled at their own loneliness yet just cannot do anything about it. I well remember the case of 'Peter', undernourished, dirty, smelly, and always alone, but hovering as close to the entrance of the school building as he could manage. Deliberation on the situation led me to try to get him involved in a lunchtime mutual-support group of students, but was told on the phone by his father: 'I'm not having my son associating with a load of drongos ... I don't want him labelled.' ... I could never find a way to communicate with 'Peter' to see if there was anything the school could do to support him better. (Wearmouth, 2004, p. 8)

Some, like "Larry", interviewed in a study of adults' recollections of school, may reject any approach from teachers:

I really didn't want teachers to know me ... They just did their job and no more. I got help when I wanted it eventually. I didn't want teachers hanging around me. (Wearmouth, 2004, p. 8)

\section{"TALKING STONES"}

"Talking Stones" is a pedagogic tool that can serve as a sensitive assessment device for student self advocacy which views learners as active agents in their own learning. In doing so, it addresses the challenge of engaging with a student's perspective meaningfully in order to find a positive way through difficult situations in schools, and matches provision to real needs.

This is a powerful projective technique derived from methods related to Personal Construct Psychology and developed from Crosby's therapeutic work with adults (Crosby, 1993). It is important that teachers know of techniques such as "Talking Stones" but there are very strong ethical considerations that must also be taken into account. Young people may have very strong reasons for not wishing to disclose information about themselves. Teachers might well choose to make referrals of students and work alongside those qualified and experienced in using projective instruments such as this.

At the beginning of an interview, the student is given a pile of stones of varying shapes, sizes, colours and textures and encouraged to use these stones to explore their thoughts and feelings about school and themselves in relation to it. The student selects a stone to represent him/herself in school and discusses the attributes of the stone that have influenced his/ her choice. S/he then selects more stones to represent significant others in his/her life at school (or the domain about which there is current discussion), describes why they have been chosen, and then places them on a rectangular cloth or large sheet of paper whose edges set a boundary to the positioning of the stones and their distance from each other. Stones, their attributes and their positions in relation to each other can be seen as representing individually constructed meanings.

The "Talking Stones" technique is discussed here with reference to an interview carried out with a 15-year-old student, "Darren".

\section{Context of the Study}

Darren was a student in an urban comprehensive secondary school in a socio-economically deprived area in an East Midlands county in England. He was one of a group of ten Year 10, 14-15 year old students, mostly boys, whose behaviour had been identified as of particular concern as a 
result of high levels of school absence and reports of serious disruption in class. In an attempt to reduce student absence and the level of disruption in the classroom, an alternative curriculum which included group discussion and counselling as well as additional work experience placements was organised for them for part of the week. It was seen as important to the success of this initiative that the students themselves should be encouraged to express their feelings about themselves and their experiences of schooling, and contribute to the discussion of the provision that was being arranged. "Talking Stones" was the technique used to elicit the views of some of these students. Darren was one of the group who agreed to be interviewed. His interview took place over two separate sessions in the privacy of the office of a Head of Year at times when the group was together for discussion and counselling sessions.

\section{Darren's Story}

Darren was described by his teachers as taciturn, a bully, and a student to be feared by peers. When the class register was called he never acknowledged his name and never talked to staff about anything of personal interest to himself. At the beginning of the first interview, he was given a pile of twenty stones, asked to feel their textures, look at their colours and shapes and then select one to represent himself. He sorted through the pile and picked out a piece of lumpy grey fossilized mud that was full of holes. When asked about this stone he explained his choice in a highly pejorative way:

It's rotten right through. I'm rotten right through ... (Wearmouth, 2004, p. 9)

Darren's response was a shock to the interviewer. She had expected reticence but he had volunteered a damning, negative self portrait. He supported his "rotten" identity with a description of incidents outside school where he had been in trouble with the police for drunkenness on the street and for suspected vandalism to property. His own "rottenness", in his view, stemmed from his family background:

I come from a very bad family. My family are all thieves well, not actually my family, but my cousins are all thieves. They've all been in trouble for stealing. One of them's banged away now for stealing, and there's another one who's a drug pusher ... (Wearmouth, 2004, p. 9)

Already he had established a possible link between his reluctance to answer to his name in class and his feelings about membership of his family. The first session with Darren was interrupted after a very short period.

The interview resumed a week later. Darren was first asked to pick out a stone to show what he was like in school. He chose a small, grey, mottled stone with a very rough texture:

... it's rough ... it shows how I mess about in school.

(Wearmouth, 2004, p. 9)

The stone represented the quality of his work as well as his behaviour in class:

... it's dark grey and it's black - rough work.

(Wearmouth, 2004, p. 9)
He attributed his behaviour and lack of achievement to boredom and victimisation by teachers:

I don't like school very much because I'm just not interested. ... it's not really fair ... if you're brainy the teachers let you talk a bit and laugh a bit - not a lot, but they let you do it a bit if you're brainy, but they don't let me ... (Wearmouth, 2004, p. 9).

His sense of victimisation was increased with teachers "giving up" on him, for example, in relation to homework:

I don't think we ought to do homework. Anyway, teachers realise that I'm never going to do it. They realised that I wasn't going to do it when I was in Year 9. So eventually they gave up. (Wearmouth, 2004, p. 9)

Teachers gave up on him:

... quite a lot. If you're late three times in a week you're meant to get a detention but I don't get it. You're supposed to, but they don't give it to me. (Wearmouth, 2004, p. 9)

Teachers "giving up" on him appeared to worry him considerably. He thought there might be an intention to exclude him from the school permanently:

Actually they've said that now they're letting it all build up, and when it gets bad enough they're going to get rid of me altogether. (Wearmouth, 2004, p. 9)

In order to gain a comprehensive picture of him it was important to find out whether he had any strengths and interests on which to develop a positive intervention for the future. The interviewer asked whether there was anything that he was interested in:

The thing I'm best at is playing football for X (football team). (Wearmouth, 2004, p. 9)

He chose a medium-sized, smooth stone in vivid shades of red, purple, orange and brown to represent himself on the football pitch because:

It's got lots of different colours in it. ... The red and orange colours, show what I'm like when I'm playing football cos I have lots of different moods when I'm on the pitch, but it shows what I'm like when I'm angry. Sometimes I get angry when I get fouled on the football pitch as well. (Wearmouth, 2004, p. 9)

He talked about himself as an aggressive player on the football field:

... one thing about me when I play football - I can get very angry on the pitch. .. If I start a move and someone misses it, for example ... I start the move and get it going and pass the ball, and someone messes it up and just misses it altogether and doesn't score the goal, I get ever so angry. (Wearmouth, 2004, p. 9)

This stone was very different in colour and texture from the one that represented him in the classroom. When asked again about the lumpy grey one that he first picked out to illustrate himself at school he said: 
It hasn't got any colour. ... I haven't got any colour at school. (Wearmouth, 2004, p. 9)

Asked how well he would like to be doing with his work, he replied:

At the top for everything. (Wearmouth, 2004, p. 9)

What stopped him was that:

I like messing about. (Wearmouth, 2004, p. 9)

Asked what he would have to do to be at the top he said:

I would have to try harder and not mess about, but the problem is that to be at the top I'd have to do that - to try harder and not mess about. (Wearmouth, 2004, p. 9)

Requested to pick out a stone that represented "good work", he chose one that was whitish and smooth, a clear contrast to the small, grey, rough, mottled stone that represented both Darren as one who "messes about" and his work as "rough".

The interviewer then set out the stones to represent the two ends of an imaginary line on which both the quality of work and also standards of behaviour could be rated from "very good" to "very bad". Darren was invited to rate his work and his behaviour on this imaginary line in a number of subject areas. In English he indicated the place on the imaginary line as:

Probably just below halfway ... For work and behaviour. (Wearmouth, 2004, p. 9)

In mathematics he described himself as:

Here. Near the top ... (Wearmouth, 2004, p. 9)

He explained the reason for the difference between his achievement in mathematics and English:

I used to be just under halfway for maths as well, but I didn't like the teacher then and I asked to change sets, and I like the teacher that I've got now, and my work is much better ... (Wearmouth, 2004, p. 9)

He felt his behaviour was:

Near the top as well. (Wearmouth, 2004, p. 9)

Because:

I like the new maths teacher. ... Because he explains things to you. He's funnier as well. (Wearmouth, 2004, p. 9)

To represent the new mathematics teacher he chose:

That bright orange stone. (Wearmouth, 2004, p. 9)

There was a second orange stone in the pile, but Darren had selected the first:

Because it's smoother. This one is smoother than the others ... he's a better teacher. (Wearmouth, 2004, p. 9)

For the "worst teacher", he picked up a small, mottled, grey and black stone:
I've chosen this little kind of lumpy stone 'cos she's really a bit thick. I mean, we have to correct her spellings. ... She's moody as well ... She lets some people do things and not others. If some of the girls say: "Can we go to the toilet?' she lets them go to the toilet, but she doesn't let us. (Wearmouth, 2004, p. 9)

During the remainder of the interview, the colour and texture of other stones in the pile facilitated further discussion of Darren's interests and began to open up a consideration of future prospects.

\section{DISCUSSION}

As Wearmouth, et al (2004) comment, current moves towards inclusive approaches for all students of statutory school age require a re-conceptualisation of both learning and behaviour as dynamic and interactive between students and the learning environment. Learning occurs through engagement in social situations. We need to know, and take account of, students' own perceptions and understandings in the social context in which that learning is taking place. Pedagogy therefore needs to be interactive and "intersubjective" to take account of individual meaningmaking. If this is to occur, teachers need to be able to reflect critically on notions of "behaviour difficulties", inclusion and the values associated with them (Schōn, 1983).

"Talking Stones" enabled Darren to discuss himself and his concerns in a way which enabled a much greater understanding of his perspective than had been possible prior to this. The social consequences of his view of himself as "rotten right through" seem to be very harmful. He appeared to be experiencing competing values and expectations stemming from internal idiosyncratic processes or from differing family and sub-cultural values which was leading him to rejection of everything related to school (Ravenette, 1984). Darren had gained little positive from school and was in danger of experiencing only further confirmation of his devalued status.

"Talking Stones" is a flexible pedagogic tool which enables individuals to invest meaning in concrete objects which have no intrinsic meaning themselves apart from their own "stone-ness". Stones have texture, size, shape and colour. They are mobile and can be used to represent movement. They enable students to articulate their feelings about themselves in relation to school in ways not previously open to them. Above all they move the student and meanings mediated by his/her own personal saliences to the centre of the learning process.

From a constructivist viewpoint, there is no separation between learning and personal transactions. Students actively engage in construing themselves and learning about the world through social interaction which itself shapes the pattern of their thought processes. Every act of learning, every act of deviance from social expectation, every refusal to co-operate is a personal engagement (Wearmouth, 2003). The interview technique used here enabled Darren to articulate a perception of himself and a construction of what was happening around, and to, himself that he had not 
disclosed before. The transcript provides powerful evidence of a "spoiled" identity (Goffman, 1963). He had constructed a view of himself as "rotten right through" empirically from his experiences at school where he perceived staff as waiting to rid themselves of him, from his membership of a family that he described as thieves and drug-pushers, and from his own treatment at the hands of the police. The use of "Talking Stones" allows us to glimpse more of what the student's experience is from the student's own perspective. Understanding behaviour in this way may not make an act any easier to tolerate in the mainstream class, but it does mean that the behaviour is explicable in the same way as any other. Further, it implies that it is possible to see the world more closely through learners' eyes and hold dialogue with them.

Darren had been portrayed by teachers as a dour, uncommunicative, inarticulate boy. He had been described as "at very high risk of exclusion" from his school as a result of acts of deviance such as the theft of master keys to the school premises and open verbal defiance of staff in lessons. He was also reported as uninterested in anything school had to offer except for sport, quite frequently under the influence of drugs of one kind or another, suspected by the police of petty crime in the vicinity and a personage feared by many of his peers.

Bruner (1996) comments upon the link between low self esteem and behaviour that can be experienced as challenging to the school system. Self advocacy is hugely important to the development of self esteem. '... the management of self-esteem is never settled, and its state is affected powerfully by the availability of supports provided from outside. They include above all the chance for discourse.' (Bruner, 1996, p. 37)

One of the prime responsibilities of schools, therefore, is to support the construction of a student's sense of Self through an acknowledgement of agency:

If agency and esteem are central to the construction of a concept of Self, then the ordinary practices of school need to be examined with a view to what contribution they make to these two crucial ingredients of personhood. If school is an entry into the culture then we must constantly reassess what school does to the young student's conception of his (sic) own powers (his sense of agency) and his sensed chances of being able to cope with the world both in school and after (his self esteem). (Bruner, 1996, pp. 38-9)

"Talking Stones" is a useful tool that needs to be embedded into the curriculum. In the process of developing its use with students in schools there are particular aspects which should not be ignored. As Wearmouth (2004) notes, it:

- can only be carried out on an individual basis;

- is time-consuming;

- can be intrusive. Its use is ethically questionable unless there is a positive payoff for the interviewee. Teachers using 'Talking Stones' should be aware of ethical principles associated with techniques of a counselling nature, for example those of 'nonmaleficence' and 'beneficence'. As McLeod (1998, pp. 272-3) notes, 'non-maleficence' refers to the principle of not doing any harm, and 'beneficence' to promoting human welfare. Asking personal questions may be construed as prying into a student's privacy. It raises the question: what should we do with sensitive information of this sort that is very important to an understanding of an individual, but may be used by some to damn or to reinforce the stereotype? However, raising self esteem is frequently set as a target for students seen as having a low self image. Targets of this sort may be a mockery if we are not aware of major factors in the student's background such as Darren's. There are many instances in schools where teachers may find themselves in a situation where students disclose very sensitive information about themselves. Before engaging in any activity where this is likely to happen, including using 'Talking Stones', teachers need to familiarise themselves very well with any guidelines that may exist in their own schools about handling information that may emerge from student self disclosure;

- requires an understanding of counselling theory and practice. (pp. 11-12)

In terms of practice it is important to recognise that:

True listening is an art; children will make decisions about people they can talk to and trust, and those they cannot. We know from the counselling literature that good listeners offer time, support, non directive questions, acknowledgement of feelings, reflecting back, and such non-verbal behaviour as eye contact, sitting next to (rather than opposite, behind a desk), and a basically trusting atmosphere which communicates that it is all right to speak honestly.

These are not easy situations to create in school ... (Gersch, 1995, p. 48)

\section{CONCLUSION}

One group of students whose perspective on themselves as learners and on the learning environment it is particularly important to seek is those who are disaffected from school. One way in which a technique such as "Talking Stones" lends itself to becoming a pedagogic tool in schools is in the manner in which it can lay bare problematic relationships between, typically, teenagers and certain members of staff, and open up the dialogue.

"Talking Stones" is a powerful technique and one not to be used lightly. Once a student has begun to disclose personal information, it may be difficult for an inexperienced interviewer to bring about closure in a way that leaves the student in a frame of mind sufficiently comfortable to return to regular classroom activities. The ethics surrounding its use should therefore be taken into careful consideration. To use this technique, teachers might be well advised to work alongside professionals qualified in the use of projective or counselling approaches. Nevertheless, in facilitating students' 
self advocacy, the "Talking Stones" technique has the potential to contribute to the "ordinary practices" of schools in developing students' sense of agency, self esteem and belonging in the world.

\section{REFERENCES}

Bruner, J. (1996). The culture of education. Cambridge, MA: Harvard.

Cole, T. (2004). The development and provision for children and young people "with emotional and behavioural difficulties": Past, present and future. In J. Wearmouth, T. Glynn, R.C. Richmond \& M. Berryman (Eds.), Inclusion and behaviour management in schools: Issues and challenges (pp. 17-33). London: Fulton.

Crosby, S. (1993). Unpublished manuscript, London: Centre for Personal Construct Education.

Department for Education and Employment. (1997). Excellence for all children: Meeting special educational needs. London: Author.

Department for Education and Skills. (2001). Special educational needs code of practice. London: Author.

Fahy-Bates, B. C. (1996). Aspects of childhood deviancy: A study of young offenders in open centres in the Republic of Ireland (Vols. $1 \&$ 2). Unpublished PhD thesis, University College Dublin.

Ford, J., Mongon, D., \& Whelan, M. (1982). Special education and social control. London: Routledge.

Furlong, V. (1985). The deviant pupil: Sociological perspectives. Milton Keynes: Open University Press.

Gersch, I. (1995). Involving the child. In Schools' special educational needs policies pack. London: National Children's Bureau.

Goffman, E. (1963). Stigma: Notes on the management of spoiled identity. London: Penguin.

Matthews, M. (1993). Constructivism and science education: Some epistemological problems. Journal of Science Education and Technology, 2, 359-370.

McLeod, J. (1998). An introduction to counselling ( $2^{\text {nd }}$ ed.). Buckingham: Open University Press.

Ministry of Education. (2001). Educational statistics for July 1 , 2001. Wellington: Author.

Munn, P., Cullen, M. A., Johnstone, M., \& Lloyd, G. (2001). Exclusion from school: A view from Scotland of policy and practice. Research Papers in Education, 16(1), 23-42.

Murphy, P. (1995). Sources of inequity: Understanding students' responses to assessment. Assessment in Education: Principles, Policy \& Practice, 2(3), 249-270.

National Assembly for Wales Education Department. (2001). Student support and social inclusion. Cardiff: Author.

Ogilvie, V. (1957). The English public school. London: Batsford.
Ravenette, A. T. (1984). The recycling of maladjustment. A.E.P. Journal, 6(3), 18-27.

Rudd, J. (1972). National school terminal leavers. Dublin: Gemaine (Mimeo).

Schōn, D. (1983). The Reflective Practitioner. New York: Basic.

Swan, T. D. (1978). Reading standards in Irish schools. Dublin: The Educational Company.

Wearmouth, J. (2003). Exploring the 'problem space' in special education provision in mainstream schools. Unpublished doctoral thesis. The Open University: United Kingdom.

Wearmouth, J. (2004). 'Talking stones': An interview technique for disaffected young people'. Journal of Pastoral Care in Education, 22(2), 7-13.

Wearmouth, J., Glynn, T., \& Berryman, M. (2004). Perspectives on student behaviour in schools: Exploring theory and developing practice. London: Routledge.

Wersch, J. V. (1991). Voices of the mind: A sociocultural approach to mediated action. Cambridge, MA: Harvard University Press.

Wheatley, G. (1991) Constructivist perspectives on science and mathematics learning. Science Education, 75, 9-22.

\section{AUTHOR PROFILE}

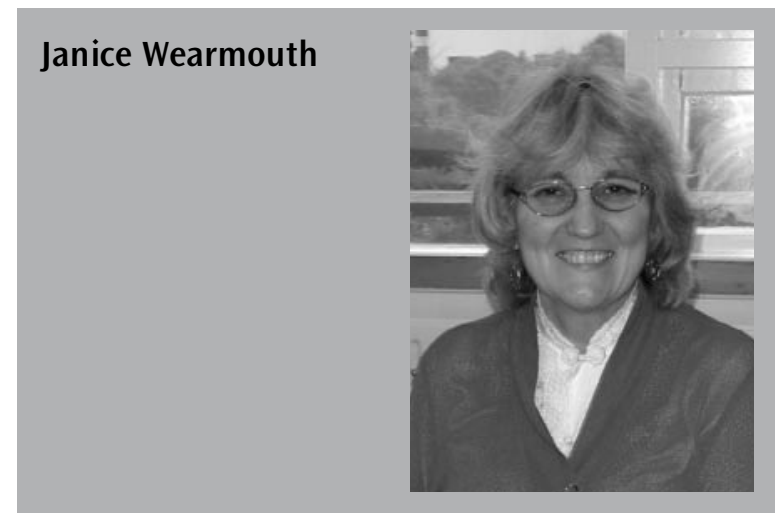

\section{Professor Janice Wearmouth}

Janice Wearmouth is Professor of Education at Victoria University of Wellington. Her research is primarily focused on bringing together a concern for the learner whose educational experience is problematic with a concern for professionals who have to deal with, and mitigate, the problems that are experienced, and open up opportunities for learning. She developed and refined "Talking Stones" during a piece of research designed to investigate the impact of school processes and practices on young people's sense of belonging to, or marginalisation from, the school community.

\section{Email}

janice.wearmouth@vuw.ac.nz 